\title{
Co-production of public services and outcomes
}

\section{Tony Bovaird, Sophie Flemig, Elke Loeffler and Stephen P. Osborne}

Co-production? Does a day go past in the public sector without us hearing about it? But what exactly does it mean? The public sector use of the term stemmed originally from the work of Elinor Ostrom (1996, p. 1073) and her colleagues Workshop in Political Theory and Policy Analysis at Indiana University, Bloomington from the 1970s onwards: "the process through which inputs used to produce a good or service are contributed by individuals who are not 'in' the same organization". Increasingly attention has also turned to its extensive origins in the service literature, where it is seen a core and inalienable element of (public) service delivery and linked inextricably to co-creating value in the lives of citizens and service users alike (Osborne et al 2016).

Current approaches now tend to focus specifically on the contributions made by citizens, whether individually as service users or collectively in communities, rather than the inputs of ALL other stakeholders. And we tend to focus not just on the coproduction of 'a good or service' but also on the achievement of behaviour change and of the outcomes desired personally by citizens and organisationally by the public sector.

However, co-production is not the only term for such 'joint production' with citizens it can be found variously under the labels of co-commissioning, co-governance, coconstruction, co-design, co-delivery, co-management and co-assessment. The recent debate on co-creation of value has added further to the complexity. Finally the public service responses to the recent global recession have also raise the question as to whether co-production is about service improvement or about levering in 'free' resources to the public service delivery equation.

However, is this all that it seems? Current workshops with practitioners in the UK reveal both that they are unaware of the embedded nature of intrinsic co-production within 'actually existing' public service delivery, and how to work with it, and that they believe that the service-enhancing potential of active co-production is not being fulfilled. Hardly what you would expect if co-production was really 'embedded' within organisational policies and practices. Moreover, much of the practice - and the rhetoric from thinktanks and interest lobbies - continues to privilege getting citizen 'voice' into public policies and services, rather than getting them to do things for themselves and for each other. Why is this? Does it really represent both a lack of understanding of the nature of service delivery, and a lack of trust in the capabilities of citizens, from politicians and public service professionals? And how does it change our understanding of the management and governance of public services 
when we appreciate that co-production is actually an intrinsic and unavoidable element of the delivery of public service rather than an optional 'add-on'?

This raises important questions: about how far the process of public service delivery and the creation of value for citizens and communities is really understood by politicians and service professionals, about the genuineness of the political commitment to greater user engagement in the design and delivery of public services, and about the extent to which service professionals are willing to share power with citizens as part of genuine co-production. Moreover co-production is not simply 'user empowerment'. The 'co' element requires the active engagement of public service professionals in co-production, yet this element is often over-looked. Finally, the 'dark-side' of co-production is rarely explored - the extent to which it can have deleterious effects on service outcomes and citizen well-being - is coproduction always a good thing?

These are important questions in today's risk-averse climate for public services, where media scrutiny of perceived failure is prolific. The number of citizens, politicians, and professionals buying into the practice is still in the minority. Is this because politicians and service managers are resistant to learning the lessons of understanding public services as services and not as products (because it shifts the focus from controlling costs to creating value), because frontline workers fear losing their professional autonomy if they have to share it with service users and other citizens, or because citizens perceive it as simply another form of privatisation by the back door? Clearly important questions about co-production still need addressing by the research community.

Unfortunately, the research base of co-production is thinner in public services than in private services, where the concept of co-production has played a core role in services management for decades. Yes, many case studies have been published in recent years, generally using qualitative methodologies. And some surveys have thrown light on the extent of intrinsic and active co-production and the motivations behind it. However, the questions raised here have not yet been answered. Moreover, there has been a shortage of well-evidenced evaluations of the results achieved when either intrinsic or active co-production of public services is managed more systematically. The determinants of successful strategies to make the most of co-production are still unclear - whilst the question of the dark side of co-production in public organisations is (almost) unrecognised. Finally, co-production has been practiced and research at the intersection of many different professional and academic disciplines, yet with little integration at a theoretical level.

Consequently, Public Money and Management is committed to taking forward this debate through a special issue dedicated to co-production both empirically and theoretically. We are seeking contributions which address these, and other, questions and which provide rigorously demonstrated results (positive and negative) 
from initiatives and strategic approaches both to engage with intrinsic co-production and to stimulate active co-production in order to improve service outcomes. We welcome quantitative and qualitative analysis. As well as theoretical integration. We look forward to your response! 